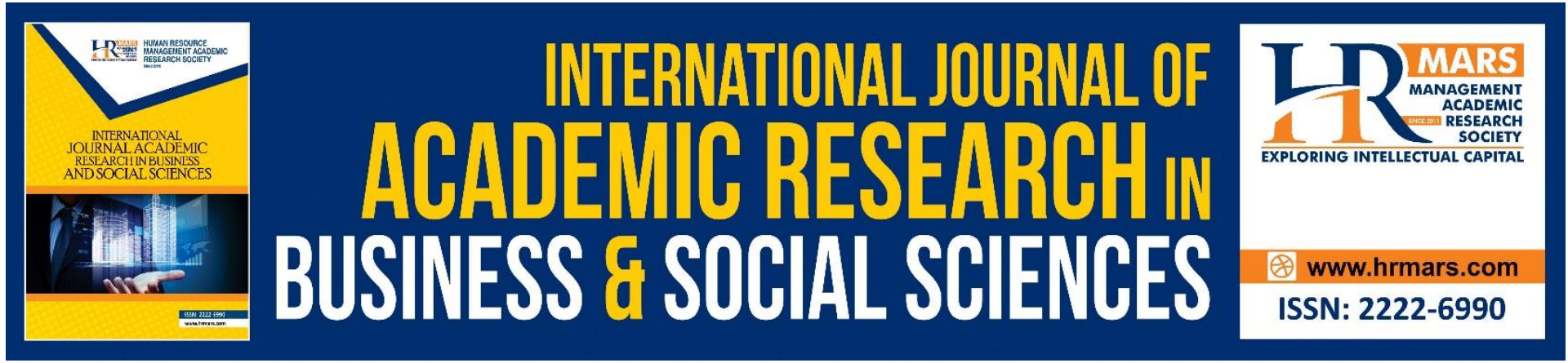

\title{
Relationship between Parenting Style, Interpersonal Conflict and Depression Symptom among University Students
}

\section{Tan Hui Yan \& Abdul Rahman Ahmad Badayai}

To Link this Article: http://dx.doi.org/10.6007/IJARBSS/v11-i6/10237

DOI:10.6007/IJARBSS/v11-i6/10237

Received: 11 April 2021, Revised: 13 May 2021, Accepted: 27 May 2021

Published Online: 19 June 2021

In-Text Citation: (Yan \& Badayai, 2021)

To Cite this Article: Yan, T. H., \& Badayai, A. R. A. (2021). Relationship between Parenting Style, Interpersonal Conflict and Depression Symptom among University Students. International Journal of Academic Research in Business and Social Sciences, 11(6), 1034-1053.

\section{Copyright: @ 2021 The Author(s)}

Published by Human Resource Management Academic Research Society (www.hrmars.com)

This article is published under the Creative Commons Attribution (CC BY 4.0) license. Anyone may reproduce, distribute, translate and create derivative works of this article (for both commercial and non-commercial purposes), subject to full attribution to the original publication and authors. The full terms of this license may be seen at: http://creativecommons.org/licences/by/4.0/legalcode

Vol. 11, No. 6, 2021, Pg. 1034- 1053

Full Terms \& Conditions of access and use can be found at http://hrmars.com/index.php/pages/detail/publication-ethics 


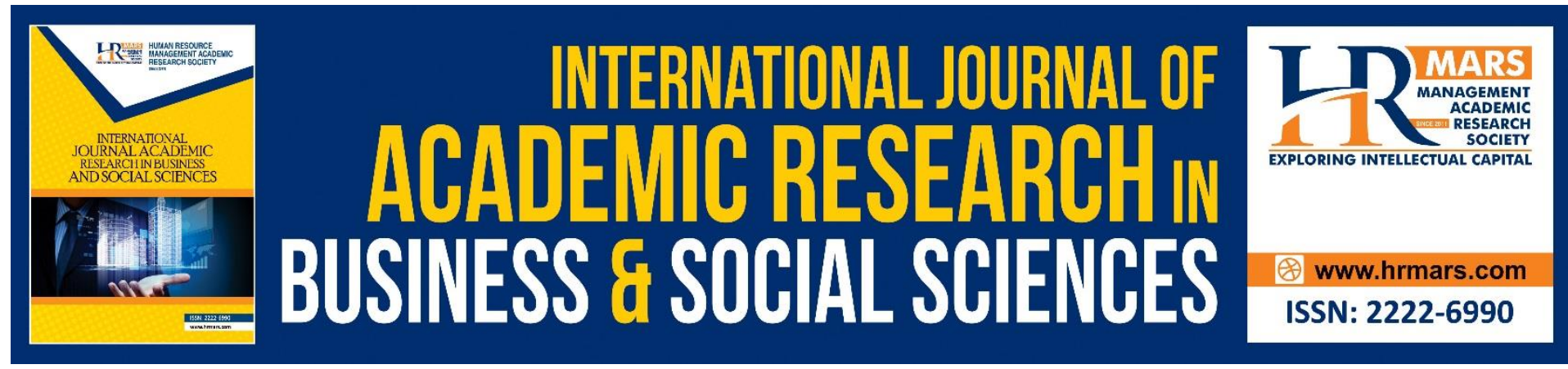

\title{
Relationship between Parenting Style, Interpersonal Conflictand Depression Symptom among University Students
}

\author{
Tan Hui Yan \& Abdul Rahman Ahmad Badayai \\ Centre of Research for Psychology and Human Well-Being, Faculty of Social Sciences and \\ Humanities, The National University of Malaysia \\ Email: arab5487@ukm.edu.my
}

\begin{abstract}
Depression is a leading cause of morbidity worldwide and the prevalence of depression among university students is higher than general population. However, studies on parenting style, interpersonal conflict and depression symptom of university students are still lack in the context of Malaysia studies. Therefore, this study aimed to examine the relationship between parenting style, interpersonal conflict and depression symptom among university students. This study was conducted at the main campus of The National University of Malaysia (UKM) and the respondents consisted of 385 UKM undergraduate students. The survey method was conducted using questionnaires that included research instruments such as Parental Authority Questionnaire (PAQ), the adapted Interpersonal Conflict At Work Scale (ICAWS) and Beck Depression Inventory-II (BDI-II) through GoogleForm application. This study found that majority of UKM students had minimal level of depressive symptom. Besides, the result showed that there was a significant relationship between authoritative parenting style, authoritarian parenting style and interpersonal conflict with depression symptom among UKM students. Nevertheless, the result showed that there was no significant relationship between permissive parenting style and depression symptom among UKM students. Furthermore, this study showed that parenting style and interpersonal conflict have influence on depression symptom among UKM students. The findings of the study also showed that there were no significant differences in the level of students' depression symptom according to gender. This study has provided an insight for a more profound future research on the issue of university students' depression symptom with parenting style and interpersonal conflict.
\end{abstract}

Keywords: Parenting Style, Interpersonal Conflict, Depression, Symptom, University Students

\section{Introduction}

Depression is a mental disorder that causes a person to be in a state of prolonged sadness, loss of interest in daily activities, low self-esteem, have guilty feelings, sleep disturbances, loss of appetite and lack of concentration. According to Hetherington and Stanley (1997), depression will result in cognitive and behavioural changes. These changes involve somatic symptoms that can lead to headaches, irritability, agitation and fatigue in a patient with 
depression. Individuals with chronic depression are also at risk of suicide (Gotlib \& Hammen, 2009).In fact, depression could impact individuals at any life stage, especially during adolescence andearly adulthood. The National Survey of Health and Morbidity III (NHMS III) found that young Malaysians aged 16 to 24 years old had the highest prevalence of acute and chronic suicidal ideation compared to other age groups (Institute for Public Health, 2006). Furthermore, according to Ranita Manap, Sohana Abdul Hamid and Marhaini Abdul Ghani (2019), university students are a unique group facing a period of critical transition from adolescence to adulthood, and this transition is considered to be one of the most stressful situations in one's life. This is because university students who face various challenges including learning to live independently, academic stress and planning a future career (Uehara et al., 2010) are prone to depression (Shamsuddin etal., 2013). Thus, this study aimed to examine the level of depressive symptom among students from The National University of Malaysia (UKM).

It is crucial to understand the risk factors of depression among university students comprehensively so that prevention and treatment can be done. One of the factors that contribute to university students' depression is parenting style. Darling and Steinberg (1993) defined parenting styleas the attitude and behaviour of parents towards children, and it is an emotional climate in which parental behaviour is shown. Parenting style also defined based on two dimensions of parental behaviours: warmth and control (Baumrind, 1971; Lamborn et al., 1991; Maccoby \& Martin, 1983). Warmth is the level of responsiveness and acceptance of parents to the needs of children. It includes elements such as the expression of positive feelings and active parental support for children when children are distressed. Control refers to the management of child behaviour by imposing strict rules, imposing rules that are less than necessary or not imposing any rules (Baumrind, 1993; Darling \& Steinberg, 1993). Based on these two dimensions, four types of parenting styles have been distinguished (Lamborn et al., 1991; Maccoby \& Martin, 1983). Firstly, parents who are warm and practice a moderate level of control are classified as authoritative. These parents will use inductive discipline and explain the reasons for their decisions to children as a way tocontrol children's behaviour. For authoritarian parenting style, parents exert a high level of control and low warmth. Parents who implement a permissive parenting style have high warmth but lack of control over their children. Lastly, parents with low warmth and control are categorized as uninvolved. Each of these parenting styles reflects differences in parenting values, practices and behaviours, and therefore it seems to have a great impact on the individual's personal development and mental health.

Other factors such as interpersonal conflict also need to be emphasized in understanding the depression of university students. Interpersonal conflict can be characterized as a state of disagreement between two individuals that is often defined in terms of significant behavioural conflicts (Shantz, 1984). Previous studies showed that people with depression tend to have more interpersonal conflict (Hemmen \& Brennan, 2011; Inoue \& Kawakami, 2010; Wilhelm, Boyce, \& Brownhill, 2004; Zlotnick et al., 2000). In addition, conflict-based interactions are also associated with an increased risk of suicide (Hirsch \& Barton, 2011). Therefore, the present researchers assumed that students with high interpersonal conflict are considered to have more negative thoughts and feelings such as depression. 


\section{Relationship Between Parenting Style and Depression Symptom}

Studies on parenting style with depression symptoms often carried out by researchers either abroad or in Malaysia. This suggests that parents play an essential role in the mental health aspects of an individual. A study conducted by Kugbey and Acharibasam (2016) found a significant positive relationship between authoritarian and permissive parenting styles with adolescents' depression. Meanwhile, there was a significant negative relationship between authoritative parenting style and adolescents' depression. Kugbey and Acharibasam (2016) proposed that the relationship between authoritarian parents and children is usually characterized by constant conflict and punitive control. Consequently, although adolescents educated through authoritarian parenting style are not involvedin problematic behaviours, they have poor social skills, low self-esteem and high levels of depression (McGinn, Cukor, \& Sanderson, 2005; Mezulis, Hyde, \& Abramson, 2006). Research by Sanjeevan and Zoysa (2018) also found that there was a significant relationship between parenting style with depression, anxiety and stress. Further, authoritative parenting style was associated with a lower level of depression and stress, while neglectful parenting style was associated with a higher level of depression and stress. Moreover, a previous longitudinal study showed that authoritative parenting style was associated with few depression symptoms during adolescence and continue to be associated with few depression symptoms two and four years later, during young adulthood (Liem, Cavell, \& Lustig, 2010). Thus, hypothesis 1 are as follow:

H1: There is a significant relationship between parenting style and depression symptom among UKM students

H1a: There is a significant relationship between authoritative parenting style and depression symptomamong UKM students

$\mathrm{H1b}$ : There is a significant relationship between authoritarian parenting style and depression symptomamong UKM students

H1c: There is a significant relationship between permissive parenting style and depression symptom among UKM students

\section{Relationship Between Interpersonal Conflict and Depression Symptom}

Interpersonal conflict is viewed as a predictor of stronger psychological distress than social support (Schuster, Kessler, \& Aseltine, 1990). Evidence showed that excessive or unmanageable conflict is associated with depression among adolescents and adults (Forehand et al., 1988). A study conductedin China found a positive relationship between interpersonal conflict with depression and stress among undergraduate students (Huang, Lv, \& Wu, 2016). This finding is similar to He et al. (2019), proving that conflict between adolescents with parents, teachers and peers is associated with high levels of depression symptom among adolescents. Besides, Inoue and Kawakami (2010) also showed that the association of interpersonal conflict with depression among males with high socioeconomic status was significantly greater than males with low socioeconomic status. Thus, hypothesis 2 is as follow:

H2: There is a significant relationship between interpersonal conflict and depression symptom amongUKM students 


\section{Influence of Parenting Style and Interpersonal Conflict on Depression Symptom}

According to the study of Radziszewska et al. (1996), there is a significant effect of parenting style on depression symptom and conflict between family and adolescents. Similarly, Kugbey and Acharibasam(2016) found that adolescents' depression level is significantly influenced by parenting style and gender differences. As for the aspects of interpersonal conflict, Nazir and Mohsin (2013) reported thatinterpersonal conflict, coping styles and aggression predict depression significantly. Also, Lewinsohn, Gotlib and Seeley (1995) demonstrated that interpersonal conflict with parents could predict the onset of major depressive disorder (MDD) and psychoactive substance use disorder (SUD). Thus, hypothesis3 is as follow:

H3: There is an influence of parenting style and interpersonal conflict on depression symptom amongUKM students

\section{Gender Differences in The Level of Depression Symptom}

Gender is a variable that is often used in studies related to depression. Most recent studies have reported that the prevalence of depression among female is higher than male (Albert, 2015; Girgus \&Yang, 2015; Rössler, 2016). For instance, Laboviti (2015) and Ozer et al. (2011) found a gender difference in the level of depression symptom in which females had higher levels of depression symptom than males. These differences could be due to the vulnerability of female in terms of biological, psychological and social aspects that drive females at high risk of experiencing depression (Girgus \& Yang, 2015). Thus, hypothesis 4 is as follow:

H4: There are significant gender differences in the level of UKM students' depression symptom

\section{Methodology}

\section{Study Design and Participants}

This study used a quantitative-based cross-sectional design where the survey method was conductedusing questionnaires through the Google Form application. The survey method was chosen because itallows researchers to make extensive coverage and get responses easily from a large sample (Asmawati, 2015). The population of this study involved a total of 11959 undergraduate students for the 2019/2020 academic session from The National University of Malaysia (UKM) located in Bangi. Besides, several criteria have been set for the sample of this study: (i) the sample should be in the age ranged from 20 to 24 years old; (ii) the sample must be an undergraduate student of UKM, the Bangi campus; (iii) the sample should be in the first to the fourth year of study; (iv) the sample is being studied at eight faculties of UKM, the Bangi campus. Based on the sample size determination table of Krejcie andMorgan (1970), the minimum sample size for a population of 11959 students was 375 students. Finally, a total of 385 students participated in this study. The sampling method used was stratified random sampling, where the minimum sample size was divided by the total population size and then multiplied by each stratum population, which was the number of students in each faculty. In the present study, the population was divided into eight strata according to the eight faculties at UKM, Bangi.

\section{Measures}

All the research instruments selected in this study were in English and developed by Western researchers. Therefore, the original research instruments in English have been 
translated into the Malay language through back-to-back translation to suit the context of Malaysian culture. The instruments were translated with the assistance of two English Language Studies Program students.

\section{Demographics}

The information that needs to be collected from the participants was age, gender, race, academic year, and faculty. Participants were required to provide faculty information because the researchers want to ensure that students from each faculty participate in this study and not just focus on one faculty only.

\section{Parental Authority Questionnaire (PAQ)}

The Parental Authority Questionnaire (PAQ) was developed by Buri (1991) to measure an individual'sperception or evaluation of the parenting style practised by their parents. This instrument was build based on the theory of parenting style proposed by Baumrind in 1971 . The PAQ was suitable for malesand females in the developmental stage of late adolescence or early adulthood. Two forms of PAQ have been designed, where one form of PAQ assesses the maternal parenting style while another form of PAQ assesses the paternal parenting style. The statements in both forms of this instrument were the same. Thus, this study used the PAQ in maternal form. The PAQ is a 30-items scale consisting of three subscales, 10 items in each subscale, which evaluate authoritative, authoritarian and permissiveparenting styles. Items were scored on a 5-point Likert scale ranging from (1) strongly disagree to (5) strongly agree. Item scores on each subscale were added to obtain the total score for each subscale. The score range for each subscale is from 10 to 50, where higher scores on each subscale indicate parents are more likely to adopt that parenting style. In this study, the PAQ had an acceptable degreeof internal consistency as a whole $(\alpha=0.79)$ and for the three subscales (authoritative, $\alpha=0.61$; authoritarian, $\alpha=0.82$; and permissive, $\alpha=0.80$ ).

\section{Interpersonal Conflict At Work Scale (ICAWS)}

The Interpersonal Conflict At Work Scale (ICAWS), comprising four items, was developed by Spector and Jex (1998) to measure interpersonal conflict at workplace. In the present study, the ICAWS was adapted by converting interpersonal conflict at workplace to interpersonal conflict at university so that the interpersonal conflict of university students could be measured. Participants were required to answer all four adapted items to indicate how often each item occurred at the university. The ICAWSscoring method was performed using a 5point Likert scale from (1) never, (2) rarely, (3) sometimes,

(4) quite often to (5) very often. The scores on each item are summed to obtain the total score. The minimum score is 4 and the maximum score is 20 . Higher scores indicate a greater level of interpersonal conflict. In this study, the adapted ICAWS was found to have a moderate internal consistency $(\alpha=0.63)$.

\section{Beck Depression Inventory-II (BDI-II)}

The Beck Depression Inventory-Second Edition (BDI-II) is a self-report instrument used to measure depressive symptoms and the severity of depression (Beck, Steer \& Brown, 1996). Apart from adults, BDI-II was also suitable for adolescents aged 13 years old and above. BDIIl contains 21 items that measure the cognitive, affective, somatic and vegetative symptoms of depression such as sadness andfatigue. There were four statements in each item except item 16 and 18 contained seven statements to measure changes in sleep and appetite. 
Participants had to select one of four or seven statementsin each item that best described their feelings during the past two weeks, including the day of filling out the questionnaire. The BDI-II scoring method involved a 4-point Likert scale ranging from 0 to 3, where a value of 0 represents no such depressive symptoms while a value of 3 represents a high intensity of depressive symptoms. The same scoring method was used for item 16 and 18, even though these two items contained seven statements. Scores for each item were added to obtain the total score. Four levels of depressive symptom can be categorized from the total score which is minimal (0to 13), mild (14 to 19 ), moderate (20 to 28 ) and severe (29 to 63). Internal consistency for the BDI-II inthis study was $\alpha=0.92$.

\section{Data Collection}

Data of this study were collected via an online survey. Before the data collection of this study was implemented, the researchers had created a set of questionnaire through the Google Form application. The questionnaire was distributed through social media along with the questionnaire link generated by the Google Form application. The researchers explain the desired respondent criteria when distributing the questionnaire links so that the involvement of students who do not meet the criteria in this study can be avoided. Furthermore, the researchers also requested student representatives from each faculty to distribute the questionnaire link to other students. The link was closed and inaccessible to other individuals once the researchers had collected sufficient data.

\section{Statistical Analyses}

Data analysis was carried out using IBM Statistical Package for Social Science (SPSS) software version 20.0. In this study, descriptive statistics involved standardization of data conducted using percentages. Frequency is used in conjunction with the percentage as an indication of descriptive data. This study used descriptive analysis to present the demographic information and examine the participants' levelof depression symptoms. Pearson's correlation was used to identify the relationship between parenting style and interpersonal conflict with depression symptoms among UKM students, while themultiple regression analysis was used to determine the influence of parenting style and interpersonal conflict on depression symptoms among UKM students. Finally, the independent samples t-test was used to examine whether there is a significant difference in the level of depression symptoms for male and female UKM students.

\section{Results}

\section{Demographic}

A total of 385 participants who met the set criteria were involved in this study. Out of 385 participants, there were 128 (33.2\%) males and 257 (66.8\%) females. Based on the age of the participants, a total of 12 people (3.1\%) were 20 years old, 85 people (22.1\%) were 21 years old, 119 people (30.9\%) were 22 years old, 137 people (35.6\%) were 23 years old and 32 people (8.3\%) were 24 years old. In addition, the composition of participants by ethnicity showed that there were 187 people (48.6\%) are Malays, 176 (45.7\%) are Chinese, 15 people (3.9\%) are Indian and 7 people (1.8\%) belong to other ethnicity.

Furthermore, academic year and faculty of the participants were also recorded. A total of $52(13.5 \%)$ participants were in the first year of study and $111(28.8 \%)$ participants were in the second year of study. Participants in the third year of study were the most, 200 people 
(51.9\%). Meanwhile, there were only 22 (5.7\%) participants in the fourth academic year. For the participants' faculty, therewere 68 people (17.7\%) studying in the Faculty of Economics and Management, 35 people (9.1\%) studying in the Faculty of Information Science and Technology and 21 people (5.5\%) studying in the Faculty of Education. Participants studying at the Faculty of Islamic Studies were 41 people (10.6\%). The majority of participants are studying at the Faculty of Science and Technology, which is 81 peopleequivalent to $21 \%$, followed by 71 people (18.4\%) who are studying at the Faculty of Social Sciences and Humanities. Besides, 53 people (13.8\%) studying in the Faculty of Engineering and Built Environment and 15 people (3.9\%) studying in the Faculty of Law. Table 1 shows the distribution of participants based on demographic aspects.

Table 1: Distribution of participants based on demographic aspects

\begin{tabular}{llll}
\hline Demographic Aspects & & Frequency & Percentage (\%) \\
\hline Gender & Male & 128 & 33.2 \\
& Female & 257 & 66.8 \\
\cline { 2 - 4 } Age & 20 & & \\
& 21 & 12 & 3.1 \\
& 22 & 85 & 22.1 \\
& 23 & 119 & 30.9 \\
\multirow{4}{*}{ Ethnicity } & 24 & 137 & 35.6 \\
& & 32 & 8.3 \\
\cline { 2 - 4 } & Malay & 187 & 48.6 \\
& Chinese & 176 & 45.7 \\
& Indian & 15 & 3.9 \\
Academic Year & Others & 7 & 1.8 \\
\cline { 2 - 4 } & First Year & 52 & 13.5 \\
& Second Year & 111 & 28.8 \\
& Third Year & 200 & 51.9 \\
& Fourth Year & 22 & 5.7 \\
\cline { 2 - 4 } & & &
\end{tabular}

Faculty

\begin{tabular}{|c|c|}
\hline $\begin{array}{l}\text { Faculty of Economics and } \\
\text { Management }\end{array}$ & 68 \\
\hline $\begin{array}{l}\text { Faculty of Information Science } \\
\text { and Technology }\end{array}$ & 35 \\
\hline Faculty of Education & 21 \\
\hline Faculty of Islamic Studies & 41 \\
\hline $\begin{array}{l}\text { Faculty of Science and } \\
\text { Technology }\end{array}$ & 81 \\
\hline $\begin{array}{l}\text { Faculty of Social Sciences and } \\
\text { Humanities }\end{array}$ & 71 \\
\hline $\begin{array}{l}\text { Faculty of Engineering and Built } \\
\text { Environment }\end{array}$ & 53 \\
\hline
\end{tabular}




\section{Level of Depression Symptom Among UKM Students}

There are four categories of depression symptom levels according to the total Beck Depression Inventory-II (BDI-II) scores of the participants, which is minimal, mild, moderate and severe levels. Table 2 shows the frequency and percentage of participants at each level of depression symptom. Themajority of participants, 279 students $(72.5 \%)$ were found to have a minimal level of depression symptom. Meanwhile, there were 34 students $(8.8 \%)$ had a mild level of depression symptom. A totalof 39 students (10.1\%) had a moderate level of depression symptom. Students who reported having a severe level of depression symptom were the least in which there were only 33 students, equivalent to $8.6 \%$. Thus, the level of depression symptom among UKM students has been examined, and it can be said that most students had a minimal level of depression symptom.

Table 2: Level of depression symptom among UKM students

\begin{tabular}{lll}
\hline Level of Depression Symptom & Frequency & Percentage (\%) \\
\hline Minimal & 279 & 72.5 \\
Mild & 34 & 8.8 \\
Moderate & 39 & 10.1 \\
Severe & 33 & 8.6 \\
\hline
\end{tabular}

\section{The Relationship Between Parenting Styles and Depression Symptom}

Table 3 summaries Pearson's correlation values for testing the $\mathrm{H} 1 \mathrm{a}, \mathrm{H} 1 \mathrm{~b}$ and $\mathrm{H} 1 \mathrm{C}$ hypotheses. Basedon Table 3, the findings showed that there was a very weak and very significant negative relationship $(r=-.135, p=.008)$ between authoritative parenting style with depression symptom among UKM students. This suggests that the higher the parents adopt an authoritative parenting style, the lower the student's depression symptom. The findings also showed that there was a very weak and very significant positive relationship ( $r$ $=.208, p<.001$ ) between authoritarian parenting style withdepression symptom among UKM students. This indicates that the more the parents adopt an authoritarian parenting style, the higher the student's depression symptom. However, there was no significant relationship ( $r=.021, p=.683$ ) between permissive parenting style with depression symptom among UKM students. Therefore, $\mathrm{H} 1 \mathrm{a}$ and $\mathrm{H} 1 \mathrm{~b}$ hypotheses were accepted while the $\mathrm{H} 1 \mathrm{c}$ hypothesis was rejected in this study. 
Table 3: Summary of Pearson's Correlation values for testing the $\mathrm{H} 1 \mathrm{a}, \mathrm{H} 1 \mathrm{~b}$ and H1cHypotheses

\begin{tabular}{llcl}
\hline & $\begin{array}{c}\text { Depression } \\
\text { Symptom }\end{array}$ & Sig. (2 tailed) \\
\hline Authoritative parenting style & Pearson's Correlation & $-.135^{*}$ & .008 \\
Authoritarian parenting style & $.208^{*}$ & .000 \\
Permissive parenting style & .021 & .683 \\
\hline
\end{tabular}

* Correlation was significant at the 0.01 level (2-tailed)

\section{The Relationship Between Interpersonal Conflict and Depression Symptom}

Referring to Table 4, the results showed that there was a weak and very significant positive relationship $(r=.309, p<.001)$ between interpersonal conflict and depression symptom among UKMstudents. This suggests that the higher the interpersonal conflict, the higher the student's depressionsymptom. Thus, the $\mathrm{H} 2$ hypothesis was accepted.

Table 4: Correlation between interpersonal conflict and depression symptom

\begin{tabular}{lll}
\hline Depression symptom & & \\
\hline Interpersonal conflict & Pearson's Correlation & $.309^{*}$ \\
& Sig. (2-tailed) & .000 \\
& $\mathrm{~N}$ & 385 \\
\hline
\end{tabular}

* Correlation was significant at the 0.01 level (2-tailed)

Influence of Parenting Style and Interpersonal Conflict on Depression Symptom

Multiple regression analysis was conducted to examine the influence of authoritative parenting style, authoritarian parenting style and interpersonal conflict on depression symptom among UKM students. Permissive parenting style, one of the independents variables was not included in the regression model because the correlation test showed no significant relationship $(p>05)$ between permissive parenting style and depression symptom. The results of the analysis showed that the three independent variables namely authoritative parenting style, authoritarian parenting style and interpersonal conflict contributed $14.8 \%$ of the variance in the dependent variable which is depression symptom $\left(\mathrm{R}^{2}=.148\right)$. Based on Table 5 , the findings showed that authoritarian parenting style, authoritarian parenting style and interpersonal conflict were significant predictors $[\mathrm{F}(3$, $381)=22.032, \mathrm{p}<.001]$ for depression symptom. Thus, the H3 hypothesis was accepted. Also, according to Table 5, interpersonal conflict was the best significant predictor of depression symptom with a contribution of $26.6 \%(\beta=.266, p<.001)$ followed by authoritarian parenting style of $19.8 \%(\beta=.198, p<.001)$ and authoritative parenting style that accounted for $18 \%(\beta=.180, p<.001)$. 
Table 5: Multiple regression analysis predicting the contribution of authoritative parenting style, authoritarian parenting style and interpersonal conflict on depression symptom

\begin{tabular}{llll}
\hline Variables & B & Beta $(\boldsymbol{\beta})$ & Sig. \\
\hline Authoritative parenting style & -.344 & -.180 & .000 \\
Authoritarian parenting style & .317 & .198 & .000 \\
Interpersonal conflict & .863 & .266 & .000 \\
\hline
\end{tabular}

Note: $R^{2}=.148 ; F(3,381)=22.032, p<.001$

\section{Gender Differences in The Level of Depression Symptom}

An independent sample t-test was conducted to examine the differences in the level of depression symptom of UKM students according to gender. Referring to Table 6, the findings showed that there were no significant differences in the level of depression symptom [ $\mathrm{t}(383)=-1.028, \mathrm{p}=.305$ ] betweenmale students (mean $=9.50, \mathrm{SD}=11.04$ ) and female students (mean $=10.69, \mathrm{SD}=10.56)$. Thus, $\mathrm{H} 4$ hypothesis was rejected.

Table 6: Independent sample t-test for depression symptom level according to gender

\begin{tabular}{|c|c|c|c|c|c|c|c|}
\hline Variable & Gender & $\mathbf{N}$ & Mean & $\begin{array}{c}\text { Standard } \\
\text { Deviation } \\
\text { (SD) }\end{array}$ & df & $t$ & Sig. \\
\hline \multirow{2}{*}{$\begin{array}{l}\text { Depression } \\
\text { symptom }\end{array}$} & Male & 128 & 9.50 & 11.04 & 383 & -1.028 & .305 \\
\hline & Female & 257 & 10.69 & 10.56 & & & \\
\hline
\end{tabular}

\section{Discussion}

\section{Levels of Depression Symptom Among University Students}

The present results showed that the majority of participants, which is UKM students had a minimal level of depression symptom. This finding was consistent with Nguyen, Le and Meirmanov (2019) whoconducted a study of depression on domestic and international students at a Japanese international university. They found that the majority of domestic and international students had minimal or mild levels of depression symptom. University students had a minimal level of depression symptom might be due to high physicalactivity involvement. According to Talebzadeh (2014), physical activity positively influences one's behavior and feelings. Physical exercise could help to reduce the level of depression, stress and tensionwhile increasing self-confidence. Furthermore, the effects of physical activity on the depression level include an increase in self-esteem, perceptions of control, and mastery and diversion from negative thoughts (Lucas, Mekary \& Pan, 2011). Ghaedi and Azlina (2014) also showed a negative relationship between physical activity and depression level among male and female undergraduate students. It proves that the higher the involvement in physical activity, the lower the level of depression of undergraduate students. Thus, it could be said that university students had a minimal level of depression symptom when their involvement in physical activity is high. For instance, various sports programs and the good sports facilities at university encourage students to engage in physical activities. According to Bauldry (2015), highly educated individuals had a lower level of depression symptom than low-educated individuals. This is because a lower level of education is associated withmore biological symptoms, increased suicidal ideation, and suicide planning 
(Gan et al., 2012).Consequently, low-educated individuals tend to have a higher level of depression symptom. In line with the previous findings, UKM students who have a high education level showed a minimal level of depression symptoms. However, the present study was limited to UKM students and a comparison ofthe level of depression symptom between highly and low-educated individuals was not conducted.

\section{The Relationship Between Parenting Styles and Depression Symptom}

The findings showed that there was a very weak and very significant negative relationship between authoritative parenting style with depression symptom among UKM students. This finding was supported by the findings of Sanjeevan and Zoysa (2019) who found that authoritative parenting style was associated with a lower level of depression. Furthermore, the results of this study were also supported by Laboviti (2015) who showed a relationship between parenting style, especially authoritative parenting style with depression symptom among adolescents.

According to Baumrind's Parenting Style Theory, parents who adopt an authoritative parenting style have a high level of responsiveness such as showing trust and warmth to meet children's psychosocial needs while implementing adequate monitoring. In the view of the researchers, authoritative parents emphasize the rational and emotional aspects of raising children. Thus, by educating through this type of parenting style, university students can perform effective interpersonal conflict management as well as emotional crisis management behaviors and develop appropriate social behaviors. The interaction between parents and students was also positive. Thereby, the vulnerability of university students to depression could be reduced.

Besides that, this study showed that there was a very weak and very significant positive relationship between authoritarian parenting style with depression symptom among UKM students. Similar findings were also reported by Betts, Gullon and Allen (2009), who found that a high level of depression symptom was related to parenting styles characterized by low nurturance and overly highprotection. The researchers' perspective on the results of this study is that authoritarian parenting style less emphasizes the element of warmth or responsiveness. Lack of these elements will cause an individual to encounter mental health problems such as depression. The individual does not acquire sufficient support and love from his parents to meet his needs and deal with problems. The researchers' view was supported by Baumrind's Parenting Style Theory which asserts that authoritarian parents have a high demanding nature but are less responsive to children. As a result, parental warmth, nurturance and communication towards children is lacking (Kugbey \& Acharibasam,2016). Authoritarian parenting styles are associated with depression due to strict rules, lack of freedom, and individuals' inability to comment or discuss with parents (Chaveepojnkamjorn et al., 2016). These factors would lead to stress, anxiety, suffering and lack of self-esteem and eventually cause depression.

Also, the present study indicates that there was no significant relationship between permissiveparenting style with depression symptom among UKM students. This finding is inconsistent with previous results that there was a significant positive relationship between permissive parenting style with depression. In contrast, the study of Sharma M, Sharma N.R. and Yadava (2011) show that there was a significant negative relationship between 
permissive parenting style with depression. Both of these previous studies do not support the results of this study. The discrepancy between the findings of the present study and the previous studies may be explained by different samples involved in the study. Earlier studies on permissive parenting style and depression symptoms are extensively conducted on adolescents. According to Bell and McBride (2010), adolescents find it difficult to control self-impulses and make appropriate decisions when their objectives involve an emotional component during the period of transition to puberty. Adolescents are also depressed when their objectives are not achieved (Casey \& Caudle, 2013). In the context of the permissive parenting style, parents have a high level of responsiveness but less control over children's behavior. This results in children having no goals and self-control (Pearson, 2013; Sigelman \& Rider, 2008). For adolescents who have difficulty making decisions, permissive parents who lack advice or opinions result in adolescents being more likely to experience depressive symptoms. However, this study involves university students which is the emerging adults as a sample of the study. Individuals in this developmental stage were considered to have a higher decision-making ability thanadolescents because their thinking is more mature and rational. Researchers also believe that university students are individuals who have selfcontrol where they can set achievable goals and takeappropriate action to achieve them. Thus, although permissive parents are more responsive and less controlling or disciplining children, this study showed no significant relationship between permissive parenting style with depressive symptoms because university students can make appropriate decisions, have self-control and clear goals without relying on low permissive parental control.

\section{The Relationship Between Interpersonal Conflict and Depression Symptom}

The results showed that there was a weak and very significant positive relationship between interpersonal conflict and depression symptom among UKM students. This result is consistent with a previous study in China, which reported that there was a positive relationship between interpersonalconflict and depression among undergraduate students (Huang, Lv \& Wu, 2016). The explanation for this finding is that most university students usually live in university residential colleges with other students who may not know each other. University roommates may also come from a variety of cultures and social backgrounds as well as different states. Thus, university students are believed to be facing interpersonal relationships that they are less familiar. These eventswill lead to increased stress and ultimately lead to increased interpersonal conflict (McCorkle \& Mason, 2009). Researchers assume that students tend to spend more time dealing with conflict when they experience interpersonal conflict. As a result, students' time and energy for academic activities will bereduced, disrupting students' studies and academic grades. Poor academic results are associated withdepressive symptoms in university students, especially female students (Pelkonen, Marttunen \& Aro, 2003; Pelkonen et al., 2008; Reinherz et al., 1999). Feelings of inability to cope with the academic, social and emotional demands of postsecondary education such as universities and colleges can impact an individual's mental health during the period of transition to adulthood (Land \& Legters, 2002;Pelkonen et al., 2008). Hence, interpersonal conflict is indirectly related to depression symptom among university students.

\section{The Influence of Parenting Style and Interpersonal Conflict on Depression Symptom}

The results showed that there was an influence of parenting style and interpersonal conflict on depression symptom among UKM students. Specifically, this study found that 
authoritative parentingstyle, authoritarian parenting style and interpersonal conflict were significant predictors of depressionsymptoms. This study also showed that interpersonal conflict was the best significant predictor of depression symptoms followed by authoritarian and authoritative parenting styles. These results were similar to the study of Brito et al. (2015) who proved that high levels of conflict were a predictor of more depression symptoms. According to Karimova (2015), interpersonal conflict negatively influences all processes of lifeactivities because mental and emotional states can be negatively affected when a person experiencesconflict. Hence, researchers assume that stress triggered by interpersonal conflict can cause studentsto suffer depression symptoms. This view is also supported by Hammen (2009) who suggests that individuals who are more prone to stress tend to experience depression.

Apart from interpersonal conflict, the results also found that significant predictors of depression symptom among UKM students were authoritative and authoritarian parenting styles. Liem, Cavell and Lustig (2010) support the results of this study by showing that authoritative parentingstyle is a significant predictor of depression in early adulthood. Moreover, Ang et al (2017) also demonstrated a perceived negative influence of parenting styles such as authoritarian parenting style on adolescent depression symptoms. The authoritative parenting style that emphasizes warmth and responsiveness is consistently associated with positive developmental outcomes such as fewer behavioral problems and psychological symptoms (Zhong et al., 2016). Furthermore, authoritative parents also positivelyinfluence well-being among individuals facing the transition from adolescence to early adulthood (Parra et al., 2019). For example, there will have improvements in academic achievement, self-control,self-esteem and emotional well-being (Alt, 2016; Love \& Thomas, 2014; Shen, Cheah \& Yu, 2018). Thus, since university students are the ones who experience such a transition, they have a higher level of depression symptoms if their parents practice a less authoritative parenting style. Although university students were mature in various aspects, most students still live with theirparents and depend on their parents in life. This may cause parents to lack confidence in students' ability to deal with life and refuse to encourage autonomy in students. Accordingly, students may perceive parental control is high and parents are less responsive to their feelings. This is in line with Nelson et al. (2011) who suggested that authoritarian parenting styles are characterized by a low levelof warmth and high level of control. Thus, for university students who want to be more independent and make decisions according to their own will, authoritarian parents are considered to decrease theself-esteem level of students. They tend to experience depression symptoms because a vulnerability model was stating that low self-esteem contributes to depression (Orth \& Robins, 2013).

\section{Gender Differences in The Level of Depression Symptom}

The findings showed that there was no significant difference in the level of depression symptom according to gender. This result is consistent with previous studies, which showed that there was no significant difference in the level of depression symptom according to gender among first-yearuniversity students in Bangladesh (Islam et al., 2020). One possible explanation for this result is that both genders may have similar experiences. Female students are considered to have the same political rights, experience the same pressures andhave the same employment opportunities as male students. In other words, gender equality has been achieved between males and females. According to Salk, Hyde and 
Abramson (2017), the sociologicalapproach for mental health emphasizes that one factor contributing to gender differences in depression is gender inequality. This is because gender inequality is associated with discrimination against women, contributing to gender differences in depression (Belle \& Doucet, 2003). Besides, in Malaysia, which has achieved independence for more than 60 years, women are believed to have achieved a certain level of gender equality with men (Nurhafilah \& Asmak, 2018). Therefore, given that gender equality has been achieved in Malaysia, the results of this study which showed that there was no significant difference in the level of depressive symptoms of UKM students according to gender are justified.

However, Ghaedi and Azlina (2014) found that female undergraduate students had a higher level of depression than male undergraduate students. The inconsistency between the results of this study and the results of previous studies may stem from different national cultural contexts. In the opinion of the researchers, the Malaysian cultural context is more to egalitarianism where the open expression of emotions of both genders is a phenomenon that can be accepted by Malaysian society.Both genders express emotions openly and do not suppress self-feelings can be attributed to the results of this study. Nonetheless, the cultural context of Malaysia is different from the cultural context of some other countries such as Ghana which is patrician and assumes that men should not cry or exhibit sad emotions in front of others (Kugbey \& Acharibasam, 2016). Such cultural views result in men being more prone to emotional disorders such as depression.

\section{Conclusion}

The current study suggests that parenting style and interpersonal conflict are highly related to depression symptom among university students. This study raised awareness to parents, particularly authoritarian and permissive parents about the need to conduct more effective parenting style training. Such training could improve parenting skills and enable parents to build an authoritative environment. University administrators could also provide more effective intervention programs andsupport services. For instance, sharing sessions or workshops can be conducted by teaching interpersonal conflict resolution and coping skills to reduce students' stress and depression symptoms.

Several limitations need to be highlighted in this study. First, this study uses a quantitative cross-sectional survey design. The design of this study resulted in the interpretation of cause and effect not being established on the findings. Therefore, future studies are recommended to use a longitudinaldesign in their studies. However, future researchers should be reminded that longitudinal design takeslonger time and high costs. Although this study was conducted on university students, the population of this study only consisted of UKM undergraduate students. The findings cannot be generalized to the population of other university students in Malaysia or other countries. Thus, future studies should expand the geographical area of participants to the whole of Malaysia and not be limited to public universities only.

Further, this study used the Parental Authority Questionnaire (PAQ) developed by Buri (1991)to measure an individual's perception or assessment of the parenting style practiced by his or her parents. Nevertheless, this instrument only measures three parenting styles, namely authoritative, authoritarian and permissive parenting style while uninvolved parenting style is also included in the theory of parenting style by Maccoby and Martin (1983). Thus, future studies could measure parenting style by using an instrument that 
contains four parenting styles such as the Scale of Parenting Style developed by Abdul Gafoor and Kurukkan (2014). Lastly, the Interpersonal Conflict at Work Scale (ICAWS) instrument items are general and not specific to the parties that conflict with students. Hence, future studies could measure the interpersonal conflict of university students by using an instrumentthat contains items related to the conflict between students with specific parties such as lecturers, roommates and course-mates.

\section{References}

Abdul Gafoor, K., \& Kurukkan, A. (2014). Construction and Validation of Scale of Parenting Style. Guru Journal of Behavioral and Social Sciences, 2(4), 315-323.

Albert, P. R. (2015). Why is depression more prevalent in women? Journal Psychiatry Neuroscience, 40(4), 219-221.

Alt, D. (2015). Using structural equation modeling and multidimensional scaling to assess female college students' academic adjustment as a function of perceived parenting styles. Current Psychology, 35(4), 549-561.

Ang, J. K., Phang, C. K., Mukhtar, F., Osman, Z. J., Awang, H., Sidik, S. M., Ibrahim, N., \& Ghaffar, S. F. A. (2017). Association between perceived parental style and depressive symptoms among adolescents in Hulu Langat District, Malaysia. International Journal of Adolescent Medicine and Health, 30(6), doi: 10.1515/ijamh-2016-0130 Bartlett, J. E.

Asmawati, D., Getrude, C., Mariny, A.G., Siti Rozaina, K., Noor Azniza, I., Nabisah, I. \& Mohd. Makzan., M. (2015). Pengantar Psikologi. Kuala Lumpur: SJ Learning.

Bauldry, S. (2015). Variation in the protective effect of higher education against depression. Society and Mental Health, 5(2), 145-161.

Baumrind, D. (1971). Current patterns of parental authority. Developmental Psychology Monographs, 4, 101-103.

Baumrind, D. (1993). Effects of authoritative parental control on child behaviour. Child Development, 37(4), 887-907.

Beck, A. T., Steer, R. A., \& Brown, G. K. (1996). Manual for the Beck Depression Inventory-II. San Antonio: Psychological Corporation.

Bell, C. C., \& McBride, D. F. (2010). Affect regulation and prevention of risky behaviors. JAMA, 304, 565-566.

Belle, D., \& Doucet, J. (2003). Poverty, inequality, and discrimination as sources of depression among U.S. women. Psychology of Women Quarterly, 27, 1-12.

Bett, J., Gullone, E., \& Allen, S. J. (2009). An examination of emotion regulation, temperament, and parenting style as potential predictors of adolescent depression risk status: a correlation study. British Journal of Developmental Psychology, 27, 473-485.

Brito, J., Matos, A. P., Pinheiro, R. M., \& Monteiro, S. (2015). Quality of interpersonal relationships and depression in adolescence: psychosocial functioning moderatingeffect. The European Proceedings of Social \& Behavioural Sciences, 81-94.

Buri, J. R. (1991). Parental Authority Questionnaire. Journal of Personality Assessment, 57(1), 110-119.

Casey, B., \& Caudle, K. (2013). The teenage brain self-control. Current Direction in Psychological Science, 22(2), 82-87.

Chaveepojnkamjorn, W., Pichainarong, N., Adthasangsri, V., Sativipawee, P., \& Prasertsong, C. (2016). Depression and its associated factors among senior high school students in Nonthaburi Province, Thailand: A Cross-sectional Study. Journal of Public Health in Developing Countries, 2(3), 224-234. 
Darling, N., \& Steinberg, L. (1993). Parenting style as context: an integrative model. Psychological Bulletin, 113(3), 487-496.

Forehand, R., Brody, J., Slotkin, J., Fauber, R., McCombs, A., \& Long, N. (1988). Young adolescent and maternal depression: assessment, interrelations, and family predictors. Journal of Consulting and Clinical Psychology, 56, 422-426.

Gan, Z., Li, Y., Xie, D., Shao, C., Yang, F., Shen, Y., \& Zhang, J. (2012). The impact of educational status on the clinical features of major depressive disorder among Chinese women. Journal of Affective Disorders, 136(3), 988-992.

Ghaedi, L., \& Azlina, M. K. (2014). Prevalence of depression among undergraduate students: gender and age differences. International Journal of Psychological Research, 7(2), 3850.

Girgus, J. S., \& Yang, K. (2015). Gender and depression. Journal current opinion in Psychology, 4, 53- 60.

Gotlib, I. H., \& Hammen, C. L. (2009). Handbook of depression (2nd ed). New York: The Guilford Press.

Hammen, C. (2009). Adolescent Depression. Current Directions in Psychological Science, 18(4), 200- 204.

He, G. H., Strodl, E., Chen, W. Q., Liu, F., Hayixibayi, A., \& Hou, X. Y. (2019). Interpersonal conflict, school connectedness and depressive symptoms in Chinese adolescents: moderation effect of gender and grade level. International Journal of Environmental Research and Public Health, 16(12), 2182.

Hemmen, C., \& Brennan, A. P. (2011). Interpersonal dysfunction in depressed women: Impairments independent of depressive symptoms. Journal of Affect Disorders, 72, 145-156.

Hetherington, E. M., \& Stanley-Hagan, M. M. (1997). The effects of divorce on fathers and their children. In. M. E. Lamb (Eds.), The Role of the Fathers in Child Development. New York: John Wiley \& Sons, Inc.

Hirsch, J. K., \& Barton, A. L. (2011). Positive social support, negative social exchanges, and suicidal behavior in college students. Journal of American College Health, 59(5), 393398.

Huang, Y. H., Lv, W., \& Wu, J. (2016). Relationship between intrinsic motivation and undergraduate students' depression and stress: the moderating effect of interpersonal conflict. Psychological Reports, 119(2), 527-538.

Inoue, A., \& Kawakami, N. (2010). Interpersonal conflict and depression among Japanese workers with high or low socioeconomic status: findings from the Japan Work Stress and Health Cohort Study. Social Science and Medicine, 71, 173-180.

Institute for Public Health (IPH). (2006). The Third Health and Morbidity Survey (NHMS III). Institute for Public Health, National Institute of Health, Ministry of Health, Malaysia.

Islam, S., Akter, R., Sikder, T., \& Griffiths, M. D. (2020). Prevalence and factors associated with depression and anxiety among first-year university students in Bangladesh: a crosssectional study. International Journal of Mental Health and Addiction.

Karimova, L. S. (2015). Prevention of interpersonal conflicts in teenagers' environment. Procedia - Social and Behavioral Sciences, 191, 1843-1847.

Krejcie, R. V., \& Morgan, D. W. (1970). Determining sample size for research activities. Educational and Psychological Measurement, 30, 607-610. 
Kugbey, N., \& Acharibasam, J.W. (2016). The role of parenting styles and sex differences in adolescents' depression. British Journal of Education, Society \& Behavioural Science, 17(2), 1-8.

Laboviti, B. (2015). Perceived parenting styles and their impact on depressive symptoms in adolescent 15-18 years old. Journal of Educational and Social Research, 5(1), 171-176.

Lamborn, S. D., Mounts, N. S., Stcinberg, L., \& Dornbusch, S. M. (1991). Patterns of competence and adjustment among adolescents from authoritative, authoritarian, indulgent, and neglectful families. Child Development, 62(5), 1049-1065.

Land, D., \& Legters, N. (2002). The extent and consequences of risk in U.S. education. Yearbook of the National Society for the Study of Education, 101(2), 1-28.

Lewinsohn, P. M., Gotlib, I. H., \& Seeley, J. R. (1995). Adolescent psychopathology: IV. Specificity of psychosocial risk factors for depression and substance abuse in older adolescents. Journal of the American Academy of Child and Adolescent Psychiatry, 34(9), 1221-1229.

Liem, J. H., Cavell, E. C., \& Lustig, K. (2010). The influence of authoritative parenting during adolescence on depressive symptoms in young adulthood: examining the mediating roles of self-development and peer support. The Journal of Genetic Psychology, 171(1), 73-92.

Love, K. M., \& Thomas, D. M. (2014). Parenting styles and adjustment outcomes among college students. Journal of College Student Development, 55(2), 139-150.

Lucas, M., Mekary, R., \& Pan, A. (2011). Relation between clinical depression risk and physical activity and time spent watching television in older women: a 10-year prospective follow-up study. American Journal of Epidemiology, 174, 1017-1027.

Maccoby, E. E., \& Martin, J. A. (1983). Socialization in the context of the family: parent-child interaction. In. E.M. Hethington (Eds.), Handbook of child psychology, vol 4. Socialization, personality, and social development, pp. 1-101. New York: Wiley.

McCorkle, S., \& Mason, S. G. (2009). Conflict in residence halls: a preliminary study of the efficacy of roommate negotiations to reduce roommate conflict. Public Policy and Administration Faculty Publications and Presentations, 21, 12-15.

McGinn, L. K., Cukor, D., \& Sanderson, W. C. (2005). The relationship between parenting style, cognitive style, and anxiety and depression: does increased early adversity influence symptom severity through the mediating role of cognitive style. Cognitive Therapy and Research, 29(2), 219-242.

Mezulis, A. H., Hyde, J. S., \& Abramson, L.Y. (2006). The developmental origins of cognitive vulnerability to depression: temperament, parenting, and negative life events in childhood as contributors to negative cognitive style. Developmental Psychology, 42(6), 1012-1025.

Nazir, A., \& Mohsin, H. (2013). Coping styles, aggression and interpersonal conflicts among depressed and non-depressed people. Health Promotion Perspectives, 3(1), 80-89.

Nelson, L. J., Padilla-Walker, L. M., Christensen, K. J., Evans, C. A., \& Carroll, J. S. (2010). Parenting in emerging adulthood: An examination of parenting clusters and correlates. Journal of Youth and Adolescence, 40(6), 730-743.

Nguyen, M., Le, T., \& Meirmanov, S. (2019). Depression, acculturative stress, and social connectedness among international university students in Japan: A statistical investigation. Sustainability, 11(3), 878.

Nurhafilah, M. \& Asmak, H. (2018). Towards gender equality in Malaysia: legal and policy perspectives. Tun Fatimah Hashim Women Lead Conference, pp. 313-325. 
Orth, U., \& Robins, R. W. (2013). Understanding the link between low self-esteem and depression. Current Directions in Psychological Science, 22(6), 455-460.

Ozer, E. J., Flores, E., Tschann, J. M., \& Pasch, L. A. (2011). Parenting style, depressive symptoms, and substance use in Mexican American adolescents. Youth \& Society, 45(3), 365-388.

Parra, A., Sánchez-Queija, I., García- Mendoza, M. C., Coimbra, S., Oliveira, J. E., \& Díez, M. (2019). Perceived parenting styles and adjustment during emerging adulthood: a crossnational perspective. International Journal of Environmental Research and Public Health, 16(2757).

Pearson, A. L. (2013). The impact of parenting styles on the emotional regulation of adolescents. Retrieved from http://sophia.stkate.edu/msw_papers/248

Pelkonen, M., Marttunen, M., \& Aro, H. (2003). Risk for depression: a 6-year follow up of Finnish adolescents. Journal of Affective Disorders, 77, 41-51.

Pelkonen, M., Marttunen, M., Kaprio, J., Huurre, T. \& Aro, H. (2008). Adolescent risk factors for episodic and persistent depression in adulthood: a 16-year prospective follow-up study of adolescents. Journal of Affective Disorders, 106(1-2), 123-131.

Radziszewska, B., Richardson, J. L., Dent, C. W., \& Flay, B. R. (1996). Parenting style and adolescent depressive symptoms, smoking, and academic achievement: Ethnic, gender, and SES differences. Journal of Behavioral Medicine, 19(3), 289-305.

Ranita, M., Sohana, A.H. \& Marhaini, A.G. (2019). Depression, anxiety and stress among undergraduate students. Journal of Social Sciences and Humanities, 16(2), 1-7.

Reinherz, H. Z., Giaconia, R. M., Hauf, C. A. M., Wasserman, M. S., \& Silverman, A. B. (1999). Major depression in the transition to adulthood: risks and impairments. Journal of Abnormal Psychology, 108(3), 500-510.

Rössler, A. R. (2016). Sex and gender differences in mental disorders. The Lancet Psychiatry, 14(1), 8-9.

Salk, R. H., Hyde, J. S., \& Abramson, L. Y. (2017). Gender differences in depression in representative national samples: meta-analyses of diagnoses and symptoms. Psychological Bulletin, 143(8), 783-822.

Sanjeevan, D., \& Zoysa, P. D. (2018). The association of parenting style on depression, anxiety and stress among Tamil speaking adolescents in the Colombo city. Sri Lanka Journal of Child Health, 47(4), 342-347.

Schuster, T. L., Kessler, R. C., \& Aseltine, R. H. (1990). Supportive interactions, negative interactions, and depressed mood. American Journal of Community Psychology, 18(3), 423-438.

Shamsuddin, K., Fadzil, F., Ismail, W. S. W., Shah, S. A., Omar, K., Muhammad, N. A., Jaafar, A., Ismail, A., \& Mahadevan, R. (2013). Correlates of depression, anxiety and stress among Malaysian university students. Asian Journal of Psychiatry, 6(4), 318-323.

Shantz, C. (1984). Conflict and conundrums in child development. In Newsletter of the Division on Developmental Psychology, 7, 18-28.

Sharma, M., Sharma, N., \& Yadava, A. (2011). Parenting styles and depression among adolescents. Journal of the Indian Academy of Applied Psychology, 37(1), 60-68.

Shen, J. J., Cheah, C. S. L., \& Yu, J. (2018). Asian American and European American emerging adults' perceived parenting styles and self-regulation ability. Asian American Journal of Psychology, 9(2), 140-148.

Sigelman, C. K., \& Rider, E. A. (2008). Life-Span Human Development (6th ed). Belmont: Wadsworth. 
Spector, P. E., \& Jex, S. M. (1998). Development of four self-report measures of job stressors and strain: Interpersonal conflict at work scale, organizational constraints scale, quantitative workload inventory, and physical symptoms inventory. Journal of Occupational Health Psychology, 3(4), 356-367.

Talebzadeh, F. (2014). Comparing the mental health of female athlete and non-athlete students in the city of Indica. Medicine and Public Health Journal, 1, 11-15.

Uehara, T., Takeuchi, K., Kubota, F., Oshima, K., \& Ishikawa, O. (2010). Annual transition of major depressive episode in university students using a structured self-rating questionnaire. Asia-Pacific Psychiatry, 2, 99-104.

Wilhelm, K., Boyce, P., \& Brownhill, S. (2004). The relationship between interpersonal sensitivity, anxiety disorders and major depression. Journal of Affective Disorders, 79(13), 33-41.

Zhong, X., Wu, D., Nie, X., Xia, J., Li, M., Lei, F., \& Mahendran, R. (2016). Parenting style, resilience, and mental health of community-dwelling elderly adults in China. BMC Geriatrics, 16(1).

Zlotnick, C., Kohn, R., Keitner, G. \& Grotta, D. A. S. (2000). The relationship between quality of interpersonal relationships and major depressive disorder: findings from the National Comorbidity Survey. Journal of Affective Disorders, 59(3), 205-215. 